\title{
Tracing pollution from the dismantling of oil production equipment and landfills as water pollution sources using mercury dust and a stable carbon isotope
}

\author{
K. Haarstad \\ Nibio, Norwegian Institute for Bioeconomy Research, Norway
}

\begin{abstract}
Polluted soil locations as well as solid waste landfills can be significant sources of potential pollution of the soil, biomass and both the surface and the groundwater. The management of the polluted soil sites in Norway is regulated according to the health risk related limits of target pollutants, focusing primarily on the presence of the eight key heavy metals and ten groups of organic pollutants in the top $1 \mathrm{~m}$ of soil, and to a risk based evaluation of the site leaching. The landfills are evaluated in a same way but the fate of the pollutants originating there is also supposed to be monitored using tracers. Tracing the sources and their effects can be complicated and expensive. Diffuse discharges of leachate from landfills are difficult to monitor since they typically originate under large volumes of waste. Typically, no adequate sampling or monitoring equipment is installed prior to when the landfilling operation begins. Groundwater flows are also hard to predict both in space and time and generally their scale asks for a very complex sampling strategy. The exact amount of water entering a landfill is also difficult to control and monitor due to typically large and heterogeneous areas involved, with differing evapotranspiration, infiltration and runoff characteristics. In this report we present cases of heavy metal pollution originating from a former oil production equipment scrapyard and case studies of complex pollution coming from traditional municipal solid waste landfills. Evaluation of tracers and the geostatistical modelling of their distribution and concentrations in order to evaluate the location of sources and the extent of pollution (plumes) was used. The analyses are cost reduction optimized. A total of 7 landfills were sampled over several years. The most effective tracer for the leachate description seems to be the carbon-13 isotope $\left({ }^{13} \mathrm{C}\right)$. At some polluted sites the pollutants can be carried a
\end{abstract}


great length due to wind erosion. Geostatistical methods and the software Grapher were applied. It became obvious that the public health focused risk assessments become difficult when the inflicted areas are large.

Keywords: heavy metals, leachate, dust, geostatistics.

\section{Introduction}

Tracing of pollutants in the environment is often not a straightforward matter. Mercury $(\mathrm{Hg})$, for example, can be difficult to measure in water samples, especially the inorganic species. Dust transport makes both locating and sampling challenging. Oil and gas not only contain hydrocarbons, but also metals, in particular those elements occurring as organic compounds. Examples of such metals are mercury $(\mathrm{Hg})$, vanadium $(\mathrm{V})$, chromium $(\mathrm{Cr})$, arsenic (As), and zinc (Zn) [1]. Organic metal compounds are usually very toxic. Radioactive components in the oil and the related aqueous brine are also typically present. The origin of these differs from the origin of the metal organic compounds. Most rocks contain radioactive components (NORM) and uranium and thorium are usually present as oxides or silicates, compounds of very limited solubility. In the uranium series, radium $(\mathrm{Ra})$ is the first element to be soluble in brine. The noble gas radon $(\mathrm{Rn})$ prefers remaining as gas in non-polar environment like oil and gas, rather than entering very saline aqueous brine found in the oil reservoir. This noble gas resulting from the decay of radium, diffuses into the non-polar phase. This is a rather slow process and its only isotope with sufficient half-life is ${ }^{222} \mathrm{Rn}$. The daughter elements of ${ }^{222} \mathrm{Rn}$ all have their half-lives too short to be able to leave their environment until lead ${ }^{210} \mathrm{~Pb}$ with the half-life of 22.2 years. This is illustrated in Figure 1 showing the radioactive series from ${ }^{238} \mathrm{U}$. The main decay routes and half-lives are indicated. At oil and gas handling installations the equipment is exposed to oxidation agents and thus corrosion. In the hydrocarbon fluids there may be traces of water vapour, $\mathrm{CO}_{2}$ and $\mathrm{H}_{2} \mathrm{~S}$. These components may attack iron forming what is typically known as black powder, $\mathrm{FeS}_{\mathrm{x}}$. Lead ${ }^{210} \mathrm{~Pb}$ combines with the sulphide due to its high affinity to it.

A landfill monitoring situation can become very complex as a large number of very different compounds could disperse in different ways. Tracing these sources and their effects can be complicated and expensive. Diffuse discharges of leachate from landfills are subject to legal action in Norway if they are greater than $5 \%$ of the water volume entering the landfill. Such volumes are difficult to monitor since they occur under large volumes of waste and the monitoring would require adequate sampling or monitoring equipment installed prior to landfilling. Heavy carbon $\left({ }^{13} \mathrm{C}\right)$ is a stable isotope sensitive to biochemical fractionation [2]. In an anaerobic reactor or landfill the major end products of fermentation and methanogenesis are $\mathrm{CH}_{4}$ and $\mathrm{CO}_{2}$, the former predominantly as a gas of low concentrations in water, and the latter as inorganic bicarbonate (Figure 1) with high water concentrations and therefore a greater presence of ${ }^{13} \mathrm{C}$.

Soil sample analyses of heavy metals and concentration of heavy carbon in water samples are used to trace the transport of pollutants by diffuse dust and leachate. 
Solubility in water
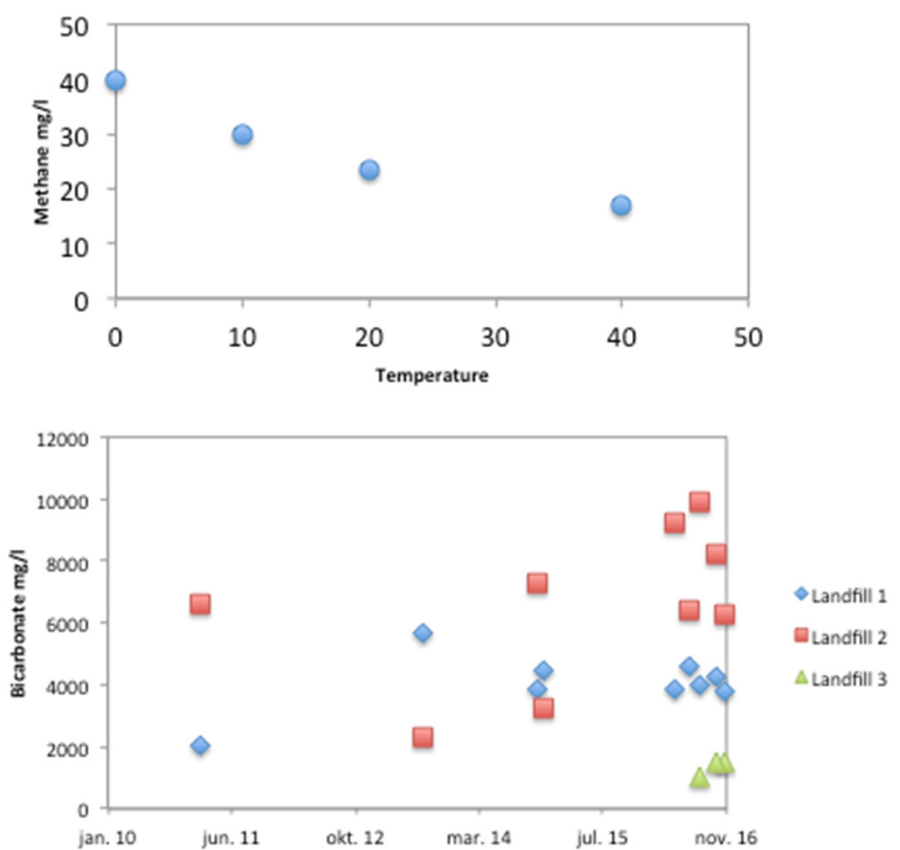

Figure 1: Solubility of methane $\left(\mathrm{CH}_{4}\right)$ in water (top) and measured concentrations of bicarbonate $\left(\mathrm{HCO}_{3}\right)$ in leachate in three Norwegian landfills.

\section{Methods}

Processing of decommissioned oil exploration equipment is potentially likely to pollute the environment with heavy metals and organic pollutants. The Norwegian Agency for Environmental Protection (formerly SFT, currently MD) provides guidelines regarding health based limit values for substances in soil, water and sea sediments $(1,2)$. Samples were taken at three different depth profiles as indicated in Figure 2. First - vegetation removed, surface made flat at the top, and sampling soil at 0 to $10 \mathrm{~cm}$ depth. Second - establishing another flat surface at $10 \mathrm{~cm}$ depth and sampling the depth 10-20 cm. Third - establishing yet another flat surface at $30 \mathrm{~cm}$ depth and sampling soil at 30 to $50 \mathrm{~cm}$ depth. Every sample is a composite sample of 4 to 5 subsamples. The samples were kept in plastic bags. The soil density was measured by pressing metal rings down at each of the sampling surfaces and collecting undisturbed samples, which were subsequently dried at $105^{\circ} \mathrm{C}$. The exact sampling locations were determined by GPS and later confirmed by checking with Statens kartverk (official Norwegian mapping system). The soil samples were analysed using modified EPA methods 200.7 and 200.8 (ICPSFMS), after dry sieving ( $2 \mathrm{~mm}$ ). Dry matter was established after drying at $105^{\circ} \mathrm{C}$ 
according to Swedish standard (SS 028113). Soil extraction was carried out in $5 \mathrm{ml}$ of concentrated $\mathrm{HNO}_{3}$ and $0.5 \mathrm{ml}$ of $\mathrm{H}_{2} \mathrm{O}_{2}$ in a microwave oven. Radionuclides were determined by $\mathrm{HR}$ gamma spectroscopy (CZ_SOP D06_07_367, ČSN ISO 10 703).

\section{Results and discussion}

Small dust particles have the tendency to infiltrate the environment with the runoff and enter the subsurface. Figure 2 shows contour lines of concentration of $\mathrm{Hg}$ with depth in the vicinity of a scrapyard dealing with decommissioned offshore oil production equipment, as determined by Surfer, located at the bottom right corner of the graphs. The $\mathrm{Hg}$ presence pattern was similar for the top and the middle sampling layer, but different to the bottom one. This was also the case for As and $\mathrm{Pb}$.
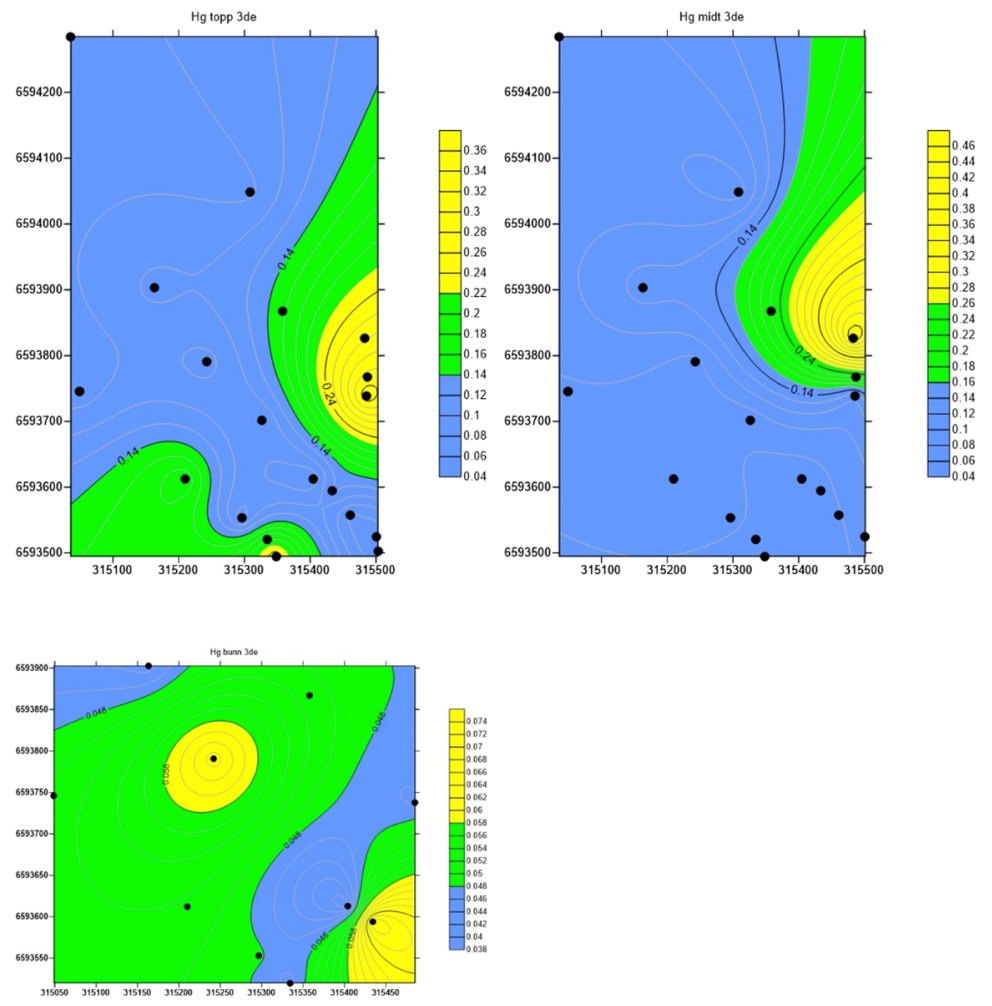

Figure 2: Iso-contours of soil $\mathrm{Hg}(\mathrm{mg} / \mathrm{kg} \mathrm{DM})$ in the top (top left), middle (top, right) and bottom layers. 
Figure 3 shows estimates of how much mercury the plant must have emitted in the past in order to increase the concentration of mercury in the top $10 \mathrm{~cm}$ from the assumed true background (TB) level, which is presumed equal to the mean concentration in the bottom sampling level, $0.05 \mathrm{mg} / \mathrm{kg}$, as well as increase the concentrations to exceed the Guidelines limit value of $0.54 \mathrm{mg} / \mathrm{kg}$, assuming an average density of the top layer is equal to the measured density of $1.3 \mathrm{~kg} / \mathrm{dm}^{3}$. Also shown are the estimated emissions if we assume that the measured concentrations are only $10 \%$ of the actual emissions, adjusted to erosion impact.

The annual limit of mercury released to the sea by the plant is $0.040 \mathrm{~kg}$ [3].

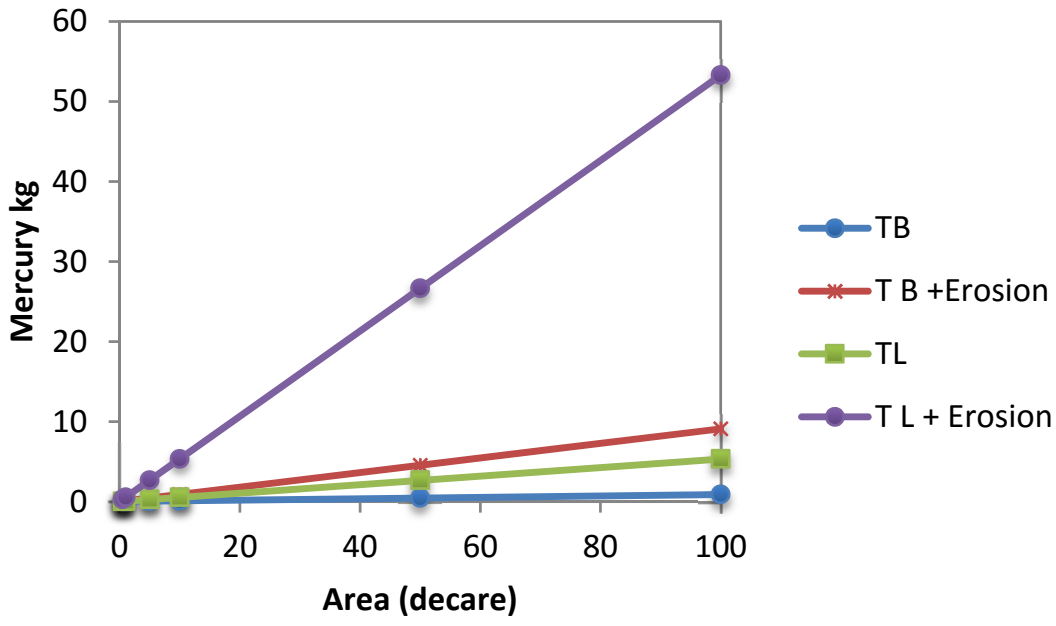

Figure 3: Estimated total emission of mercury $(\mathrm{Hg})$ to increase the concentration in the top layer (TB) and to cross a limit value (TL).

Of the radioactive parameters the isotope ${ }^{210} \mathrm{~Pb}$ in the soil samples was found not to be in equilibrium with the expected decay. Three core samples of $100 \mathrm{~mm}$ each, ranging from $0-100 \mathrm{~mm}, 100 \mathrm{~mm}-200 \mathrm{~mm}$, and $200 \mathrm{~mm}-300 \mathrm{~mm}$ (when possible) at randomly selected sites. The radioactivity of the samples was compared for ${ }^{234} \mathrm{Th},{ }^{226} \mathrm{Ra}$, and ${ }^{210} \mathrm{~Pb}$. The samples with the radioactive equilibrium between two or more of the nuclides could be observed, were then used for background level calculations. The uncertainty was high. The background value determined was $34,2 \pm 12,3 \mathrm{~Bq} / \mathrm{kg}$, i.e. one standard deviation is $36 \%$. Several samples contained ${ }^{210} \mathrm{~Pb}$ at levels well above the background value plus three standard deviations (i.e. $>71.1 \mathrm{~Bq} / \mathrm{kg}$ ). These samples were all from the top $100 \mathrm{~mm}$ soil sampling level. There was a correlation between the level of mercury in the samples with high ${ }^{210} \mathrm{~Pb}$. The conclusion was that ${ }^{210} \mathrm{~Pb}$ as well as $\mathrm{Hg}$ were introduced to the soil as dust pollution from the decommissioning plant. Plumes of dust reaching the surrounding area were observed several times. ${ }^{210} \mathrm{~Pb}$ can thus be regarded as a tracer for pollution from oil and gas handling equipment. 


\section{All samples}

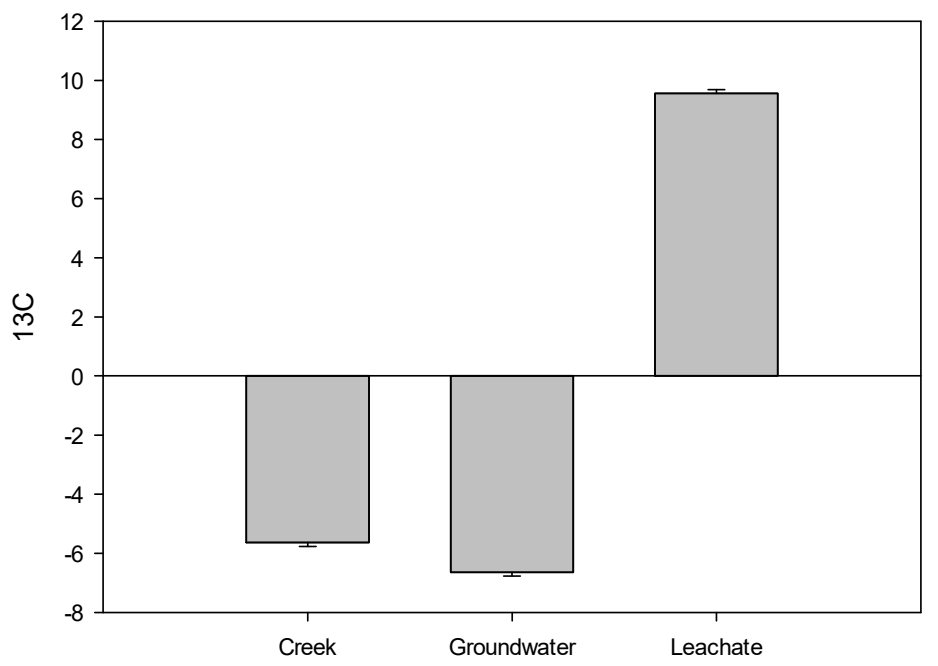

Figure 4: Isotope measurements in different water types.

\section{Grouped data}

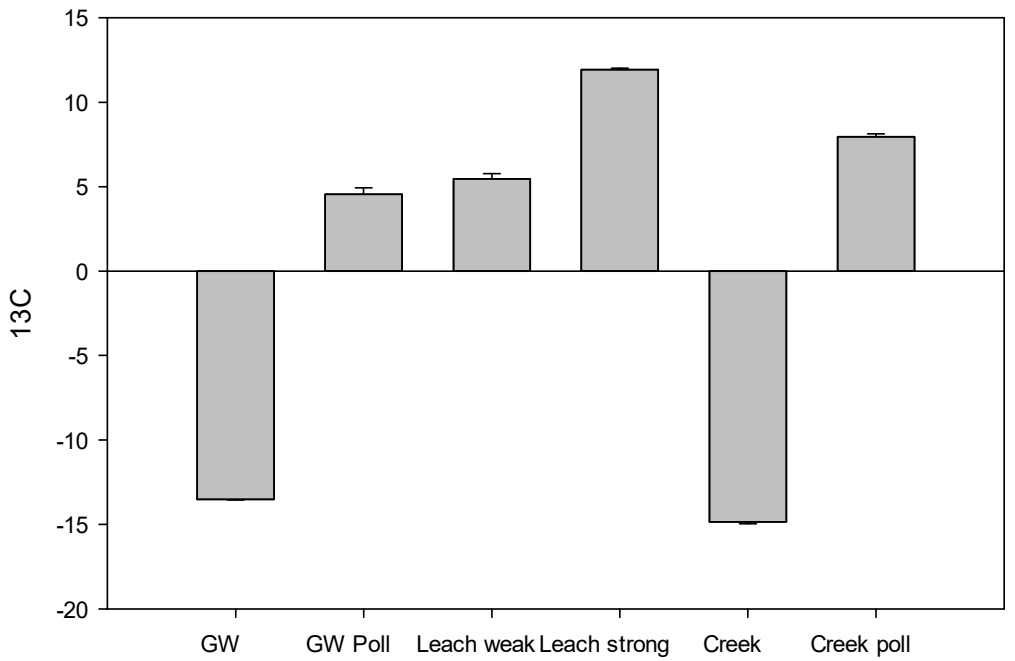

Figure 5: Isotopes sorted according to pollution. 
The amount of pollution tracers was significantly higher in the leachate samples than in the groundwater and surface water samples. Only $\delta^{13} \mathrm{C}$ was significantly different in samples identified as unpolluted, weakly polluted or polluted samples. Based on this, we conclude that the $\delta^{13} \mathrm{C}$ is a more sensitive tracer than the content of organic matter, salts, nutrients and heavy metals in the leachate. We did not find any systematic occurrence of tritium in the samples, only sporadically in the groundwater and in one of the creeks.

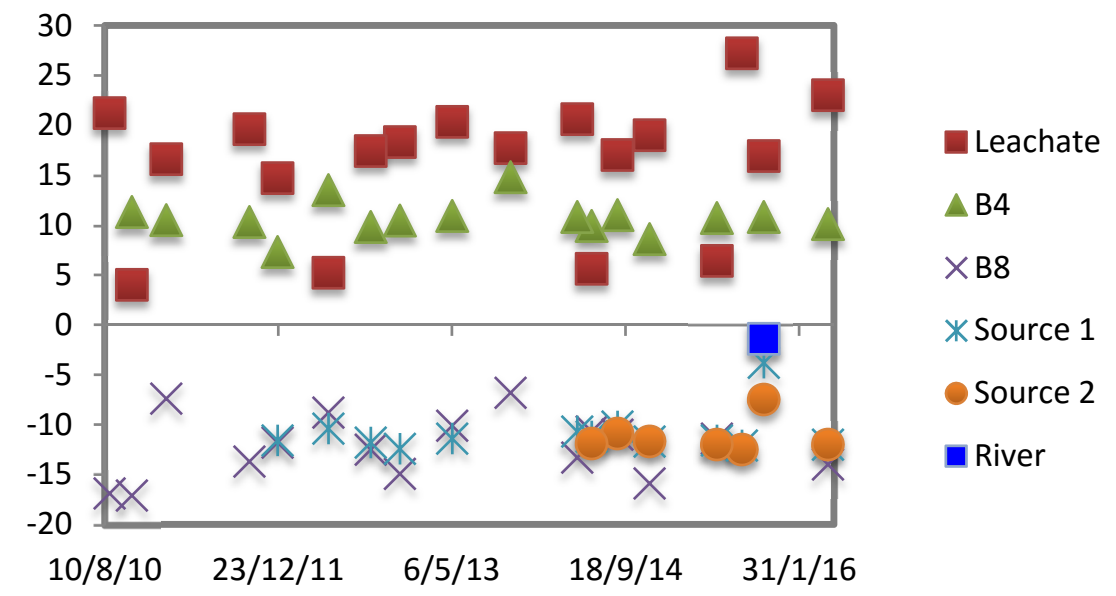

Figure 6: Time series of heavy carbon in water samples taken at one of the landfills.

\section{Conclusions}

Mercury and lead ${ }^{210} \mathrm{~Pb}$ from dust were successfully used as tracers locating an equipment scrapyard as a pollution source via dust.

When the size of a polluted area is large health based risk concentration limits in soil become meaningless.

Heavy carbon in water samples is a good tracer for solid waste landfill leachate pollution.

\section{Acknowledgements}

Jakob Hatteland of The Hatteland Group kindly approved the publication of the study at Raunes Fiskefarm. Dag Ø. Eriksen from The Institute of Chemistry, University of Oslo, analysed and reported the radioactivity data.

Alena Tetreault corrected the language of the manuscript. 


\section{References}

[1] Haarstad, K.; Eriksen, D.Ø. 2014. Sampling and Environmental Evaluation at Raunes Fish Farm in Vats, Vindafjord commune based on soil samples around the location. Bioforsk Raport 9 (145), 2014, 58 pp. (In Norwegian).

[2] Haarstad, K.; Mæhlum, T. 2012. Tracing solid waste leachate in groundwater using $\delta 13 \mathrm{C}$ from dissolved inorganic carbon. Isotopes in Environmental and Health Studies, 1-14.

[3] MD, 2007. Discharge lisence, AF Decom. 